\title{
Transcultural adaptation of the Student Nurse Stress Index to Brazil
}

\author{
Tradução e adaptação transcultural do Student Nurse Stress Index para o Brasil \\ Adaptación transcultural para Brasil de la Escala de Estrés de los Estudiantes de Enfermería
}

\section{Aline Beatriz Rocha Paula' ORCID: 0000-0003-4709-4422}

Marcia Teles de Oliveira Gouveia' ORCID: 0000-0002-2401-4947

Francisca Fabiana Fernandes Lima ORCID: 0000-0001-6110-0556

'Universidade Federal do Piauí. Teresina, Piauí, Brazil.

How to cite this article:

Paula ABR, Gouveia MTO, Lima FFF. Transcultura Adaptation of the Student Nurse Stress Index to Brazil. Rev Bras Enferm. 2020;73(Suppl 1):e20190426. doi: http://dx.doi.org/10.1590/0034-7167-2019-0426

Corresponding author:

Aline Beatriz Rocha Paula

E-mail: alinebeatriz_1995@hotmail.com

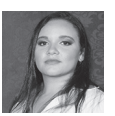

EDITOR IN CHIEF: Antonio José de Almeida Filho ASSOCIATE EDITOR: Hugo Fernandes

Submission: 08-20-2019

Approval: 12-05-2019

\begin{abstract}
Objective: to cross-culturally adapt the Student Nurse Stress Index to the Brazilian context. Method: this is a methodological study of translation and cross-cultural adaptation. We used a sample of specialists $(n=3)$ and nursing students $(n=40)$. Socioeconomic and academic questionnaires were used for data collection, assessment and the translated instrument (SNSI-Brazil). Results: most students were female (90.0\%), single (87.5\%), unemployed $(80.0 \%)$, they studied on average 11 hours per week, slept 6 hours per day; and rated the face and the content of the instrument as very good, agreeing substantially (kappa $=0.74$ and $p$-value $<0.01)$. The judges showed regular agreement in their assessments, and the SNSI-Brazil showed a good internal consistency (Cronbach's alpha $=0.80$ ). Conclusion: The SNSI-Brazil was validated for face and content, has a good internal consistency if compared to versions used in other countries.
\end{abstract}

Descriptors: Stress, Psychological; Occupational Stress; Students, Nursing; Surveys and Questionnaires; Translations.

\section{RESUMO}

Objetivo: Adaptar transculturalmente o Student Nurse Stress Index para a realidade brasileira. Método: Trata-se de estudo metodológico de tradução e adaptação transcultural. Utilizaramse uma amostra de especialistas $(n=3)$ e outra de estudantes de enfermagem $(n=40)$. Os dados foram coletados com questionário socioeconômico e acadêmico, instrumentos de avaliação e o instrumento traduzido (SNSI-Brasil). Resultados: A maioria dos estudantes era do sexo feminino $(90,0 \%)$, solteiros $(87,5 \%)$, desempregados $(80,0 \%)$, estudavam em média 11 horas/semana, dormiam 6 horas/dia e avaliaram como muito boa a face e o conteúdo do instrumento, concordando substancialmente ( $k a p p a=0,74$ e $p$-valor $<0,01$ ). Os juízes apresentaram concordância regular em suas avaliações e o SNSI-Brasil demonstrou uma boa consistência interna (alpha de Cronbach $=0,80$ ). Conclusão: O SNSI-Brasil é válido quanto a face e conteúdo e possui uma boa consistência interna, podendo ser comparado às versões utilizadas em outros países.

Descritores: Estresse Psicológico; Estresse Ocupacional; Estudantes de Enfermagem; Inquéritos e Questionários; Traduções.

\section{RESUMEN}

Objetivo: adaptar transculturalmente la Escala de Estrés de los Estudiantes de Enfermería (SNSI, sigla en inglés) a la realidad brasileña. Método: se trata de un estudio metodológico de traducción y adaptación transcultural. Se utilizó una muestra de especialistas $(n=3)$ y otra de estudiantes de enfermería $(n=40)$. Los datos se recogieron con cuestionarios socioeconómico y académico, instrumentos de evaluación y el instrumento traducido (SNSI-Brasil). Resultados: el $90 \%$ de los estudiantes era del sexo femenino, el $87,5 \%$ era soltero, el $80,0 \%$ estaba desocupado, el promedio semanal de estudio era de 11 horas/semana, las horas de sueño, 6 horas/día; se evaluó la fisonomía y el contenido del instrumento como muy bueno, de común acuerdo ( $k a p p a=0,74$ y $\mathrm{p}$-valor $<0,01$ ). Los jueces estuvieron prácticamente de acuerdo en sus evaluaciones y la SNSI -Brasil mostró una buena consistencia interna (alfa de Cronbach $=0.80$ ). Conclusión: La SNSI-Brasil es válida en términos de expresión y contenido, con una buena consistencia interna, equiparándose con las versiones utilizadas en otros países.

Descriptores: Estrés Psicológico; Estrés Ocupacional; Estudiantes de Enfermería; Encuestas y Cuestionarios; Traducciones. 


\section{INTRODUCTION}

Among health workers, some groups are more affected by stress, such as those who work in intensive care units and those in the surgical unit, because of the specific conditions and demands of their work environments. Some of these conditions are: the environment itself, critical conditions of patients, high responsibility, and a high degree of competency and skill requirements ${ }^{(1-2)}$.

More specifically, nursing has been a subject of stress-related studies. Nursing as a profession has been recognized for over half a century and has until then been considered one of the most stressful. Therefore, stress in nursing has been widely studied in different care contexts, from primary care to high complexity care, but it still deserves attention due to the peculiarities present in the professional activity, the regional differences in the care model and the management resources in the work strategy ${ }^{(1,3-4)}$.

Stress among students has been increasingly studied, since they go through a construction of their professional knowledge and, in this process, end up experiencing situations and feelings that generate anguish, fears and frustrations, which trigger pathologies $^{(5)}$.

In health courses, the curriculum has hands-on activities in which students are tested for the knowledge they have acquired during lectures. Consequently, these students experience high levels of stress, especially those in undergraduate nursing courses, due to their closeness to patients and their health problems, although they do not have the responsibilities of a nurse, they need to adapt to the routine of the course which includes examinations, practical classes and internships (lived experiences) ${ }^{(5)}$.

In the perception of nursing students, there is a negative influence of stress on their academic life, since the stressful situations they experience during the course make them more irritated, anxious, low self-esteem and/or discouraged, leading to lower academic performance and also to a greater susceptibility to depression and its consequences ${ }^{(6)}$.

However, not only stressors in the academic environment, but also socioeconomic factors are common to this population and are related to stress, such as: female, aged 18-29, having children and occupational status, for example ${ }^{(5)}$.

There are three ways to measure stress: the first one is directed to the presence of specific stressors; the second one, to the physical and psychological symptoms of stress, and the third one is related to the perception of individual stress in general, regardless of stressors ${ }^{(7)}$.

Among them, the use of the Student Nurse Stress Index (SNSI), which was built by Jones \& Johnston (1999) in the United Kingdom, and measures stress through the presence of specific stressors stands out. It is an adaptation of Beck \& Srivastava's Stress Inventory (1991) with 15 more new items, resulting in a 22-variable instrument with a simple structure, including four categories: Academic load, Clinical sources, Interface worries and Personal problems ${ }^{(8)}$.

SNSI items responses are on a likert scale and range from $1=$ absolutely stressful to $5=$ extremely stressful. The instrument has been used in several studies and has shown congruence between cross-sample factors, good internal reliability and concurrent and discriminant validity ${ }^{(9)}$.
Thus, due to the epidemiology of stress and the scarcity of instruments to evaluate Brazilian students, the objective was to cross-culturally adapt the SNSI to the Brazilian context.

\section{OBJECTIVE}

To cross-culturally adapt the Student Nurse Stress Index to the Brazilian context.

\section{METHOD}

\section{Ethical aspects}

The study project was approved and its performance at the institution was authorized by the head of the department. The risks were minimal, encompassing the possibility of embarrassment and/or discomfort regarding some questions of the instrument (translated version of the SNSI) and were minimized by clarification to them by the researchers.

\section{Design, period and setting of study}

This is a methodological study that followed the methodology proposed by Beaton et al. (2007), observing the criteria of the COSMIN protocol(10-11).

Data collection occurred in two steps during the second semester of 2018, in October and November in a Federal Higher Education Institution (FHEI) in the state of Piaui, which offers an undergraduate Nursing course. The first step occurred through the application of the evaluation instruments of the translated version to the Specialists Committee. The second one, through the application of the translated instrument (with corrections suggested by the committee), sociodemographic, academic data and the evaluation of the questionnaire translated into the sample of nursing students by the researchers.

\section{Population or sample; Inclusion and exclusion criteria}

The reference population consisted of 293 undergraduate nursing students. The type of sampling used was non-probabilistic, consisting of participants who were at the place of study at the time of data collection.

In the pre-test stage, a convenience sample of 40 students was used, corresponding to $13.6 \%$ of the total population. The inclusion criteria were: being 18 years old or older and attending at least the second year of the nursing course, and the exclusion criteriawas those who were on leave for some reason, such as maternity or medical leave.

\section{Study protocol}

Initially, the permission for the translation and cross-cultural adaptation of the instrument called Student Nurse Stress Index was requested, and its lead author granted it. The process of translation and cross-cultural adaptation occurred according to the steps proposed by Beaton et al. (2007), which are described below ${ }^{(10)}$ :

The First Step was the forward translation or translation from the foreign language (English) to the desired language (Portuguese-BR) 
by two bilingual translators whose mother tongue is Portuguese (BR). In addition, each translator included comments related to sentences with ambiguities and/or uncertainties, along with the justification for the final choice of each item.

It is worthy to emphasize that all translators participating in the study were selected according to nominations and curriculum analysis, including only those with experience in translations and/ or related area backgrounds.

The second step consisted of the synthesis and consensus of the two translations made by the researchers, who were mediators in the discussion about the differences found in each translation, since they have proficiency in both languages (Portuguese and English). Thus, from the original instrument, the first and second translators' version, a synthesis was produced resulting in a common translation.

The Third Step (backforward translation) consisted of translating the pre-final version of the instrument (in Portuguese) into the original language (English), whose purpose was to ensure that the translated version was accurate to the content of the original version, emphasizing ambiguities or conceptual errors in the translation process, as recommended by Beaton et al. (2007).

Two other bilingual translators who have English as their mother tongue and did not know the original version, translated the prefinal version into the original language, resulting in two other translations that were synthesized into only one by the researchers.

The Fourth Step was the formation of the specialists Committee that aimed to revise the versions (original and translated versions) to reach a consensus on any discrepancy found, achieving equivalence between the translated version and the original version in order to develop the pre-final version of the instrument for the field test (pre-test). This equivalence can occur in the areas:

Semantics - verifies the maintenance of the words meaning, it is based on the evaluation of the vocabulary and grammar of each item, that is, if the words have the same meanings.

Idiomatic - verifies the equivalence of colloquial expressions after translation, always preserving the original meaning. Some words, terms, and idioms are complex to translate, and if difficulties occurred in understanding some point, the judge was asked to suggest equivalent terms or idioms.

Cultural - takes culture into contextualization, experiences lived by the target population in our cultural context.

Conceptual - verifies words and concepts, as some words may be equivalent in meaning, but in relation to the concept it may not occur, so the coherence of the item in relation to what it intends to measure, as words, phrases or expressions may have semantics equivalence and be conceptually different.

The fifth Step consisted of the application of the pre-final version of the Student Nurse Stress Index - Brazil to the target population, in this case a sample of 40 nursing students from an FHEl. Performing this pre-test is essential because it allows the researcher to evaluate the adequacy of the way of data collection, detecting problems related to the content or organization of the instrument and also estimating its reliability and validity ${ }^{(12)}$.

At this stage, after applying the pre-final version, each participant also answered two questionnaires: one about sociodemographic and academic variables and the other aimed at investigating students' opinion about the Student Nurse Stress Index - Brazil in general, the items individually and suggestions about it. This stage provides useful information about how a person individually interprets the questionnaire items, as well as measuring the face and content instrument validity.

The sixth step was the submission of documentation to the Specialists Committee. At this stage, all documentation relating to the translation and adaptation process was presented to the specialists committee. It verified if all recommended stages for this process were followed and if the reports were reliable. After the analysis, the Committee decided that the process of translation and cross-cultural adaptation was approved and that the instrument could be made available for use. Figure 1 below presents a summary diagram of the process adopted during this study.

\section{PROCESS OF TRANSLATION AND CROSS-CULTURAL ADAPTATION}

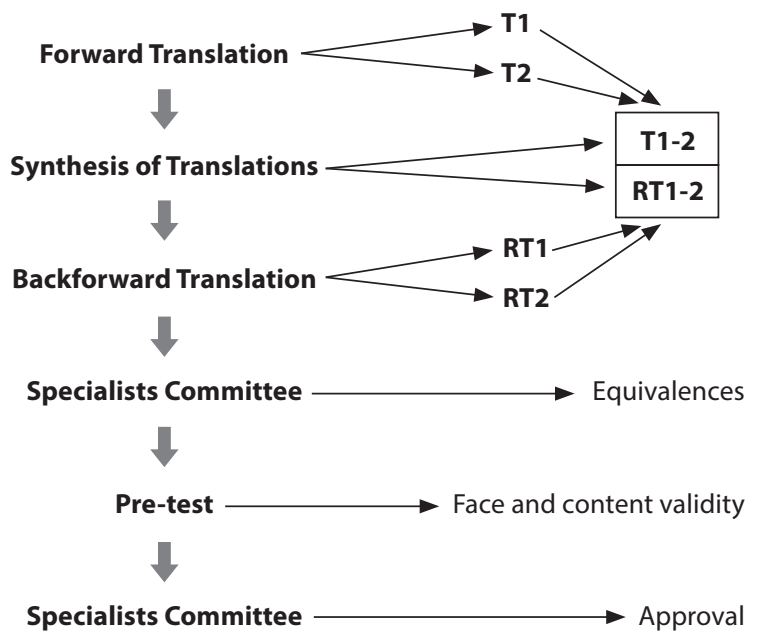

Note: T1 - Translation 1; T2 - Translation 2; T1-2 - Consolidated of translations 1 and 2; RT12 -Consolidated retro translations 1 and 2; RT1 - Retro translation 1; RT2 - Retro translation 2.

Figure 1 - Synthesis of the translation and cross-cultural adaptation process

\section{Analysis of results and statistics}

The collected data were organized in a database typed in Excel Software spreadsheet and later exported to IBM SPSS version 20 software for statistical analysis.

Initially, descriptive analyzes of the data were performed and, after that, the calculations of the Kappa coefficient and the Chronbach's Alpha. We used two types of Kappa coefficient: Cohen's Kappa coefficient, which is an association measure used to measure the agreement between the responses of two evaluators; and Fleiss Kappa which has the same purpose, but can be used for more than two evaluators ${ }^{(13-14)}$.

\section{RESULTS}

During the production of the synthesis of the Student Nurse Stress Index forward translation process by two independent translators and the consensus version of this process, some questions were observed:

For items 08 and 16 of the instrument, one of the translators raised some questions that were resolved at the time of 
consolidation of the translations. These included whether the term course referred to a subject or course as a whole; and, for clients, he suggested that the terms "patients" and "users" could be used as translations. Therefore, in view of the current discussion about the use and concept added to the terms "patient", "user" and "client", the researchers chose to keep the term "patient".

Then, the consolidated version was sent to the judges who evaluated it for semantics, idiomatic, cultural and conceptual equivalences. Tables 1 and 2 show the values obtained with the agreement test applied among the judges.

Table 1 - Kappa coefficient values for agreement among judges on semantics, idiomatic, cultural and conceptual equivalences, Brazil, 2019

\begin{tabular}{cccc}
\hline Equivalence & \multicolumn{3}{c}{ Kappa Coefficient } \\
\hline Semantics & Judge 1 & Judge 2 & Judge 3 \\
Judge 1 & 1 & & \\
Judge 2 & $0.353 *$ & 1 & 1 \\
Judge 3 & 0.000 & 0.000 & Judge 3 \\
Idiomatic & Judge 1 & Judge 2 & \\
Judge 1 & 1 & & 1 \\
Judge 2 & -0.048 & 1 & \\
Judge 3 & -0.069 & $0.463 *$ & 1 \\
Cultural & Judge 1 & Judge 2 & Judge 3 \\
Judge 1 & 1 & & \\
Judge 2 & 0.000 & 1 & \\
Judge 3 & 0.102 & 0.000 & 1 \\
Conceptual & Judge 1 & Judge 2 & Judge 3 \\
Judge 1 & 1 & & \\
Judge 2 & 0.083 & -0.058 & \\
Judge 3 & -0.076 & &
\end{tabular}

Table 2 - Kappa coefficient values for agreement among all the judges on semantics, idiomatic, cultural and conceptual equivalences, Brazil, 2019

\begin{tabular}{cc}
\hline Equivalence & Kappa Value \\
\hline Semantics & 0.1639 \\
Idiomatic & 0.2736 \\
Cultural & 0.2844 \\
Conceptual & 0.2202 \\
\hline
\end{tabular}

Regarding the judges' evaluation for the translated version of the instrument, according to the criteria of Landis and Koch (1977), Table 1 shows significant values of agreement between judges 1 and 2 for semantics equivalence (0.35) and, between judges 2 and 3 for idiomatic (0.46); which indicates a regular and moderate agreement, respectively. Table 2 shows that for semantics equivalence, the agreement was poor (0.16) and in idiomatic, cultural and conceptual equivalence was regular $(0.27$, 0.28 and 0.22 , respectively) ${ }^{(15)}$.

Judges' evaluations, comments and suggestions were taken into consideration for the modification of the T1-2 version, resulting in the pre-final version of the instrument (now called SNSI - Brazil). After the modifications made in items 04, 08, 09, 10, $15,16,17$ and 19, the SNSI - Brazil was submitted to a pre-test: it was applied in 40 nursing students of a public higher education institution. The same students also answered a socioeconomic and academic questionnaire and evaluated the SNSI - Brazil.
Academic Load

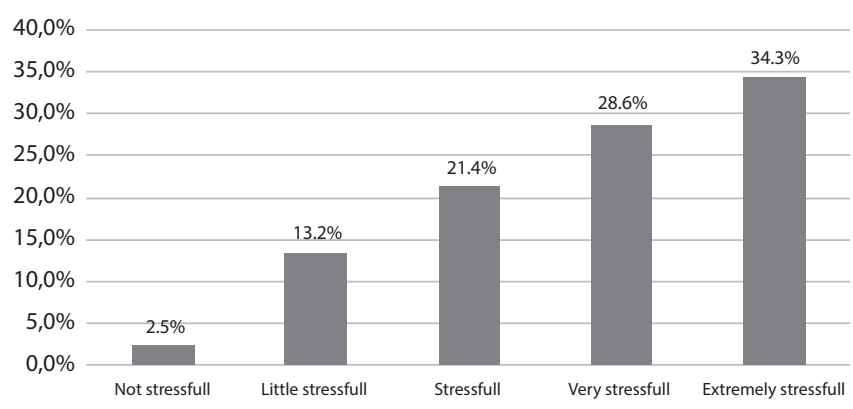

Clinical Sources

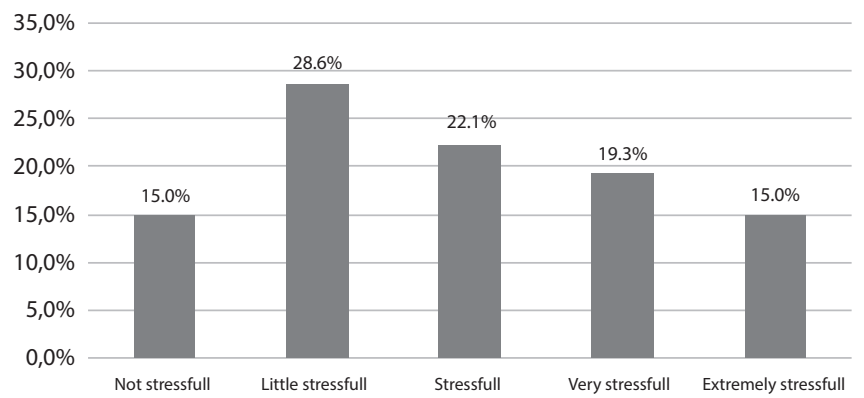

Personal Problems
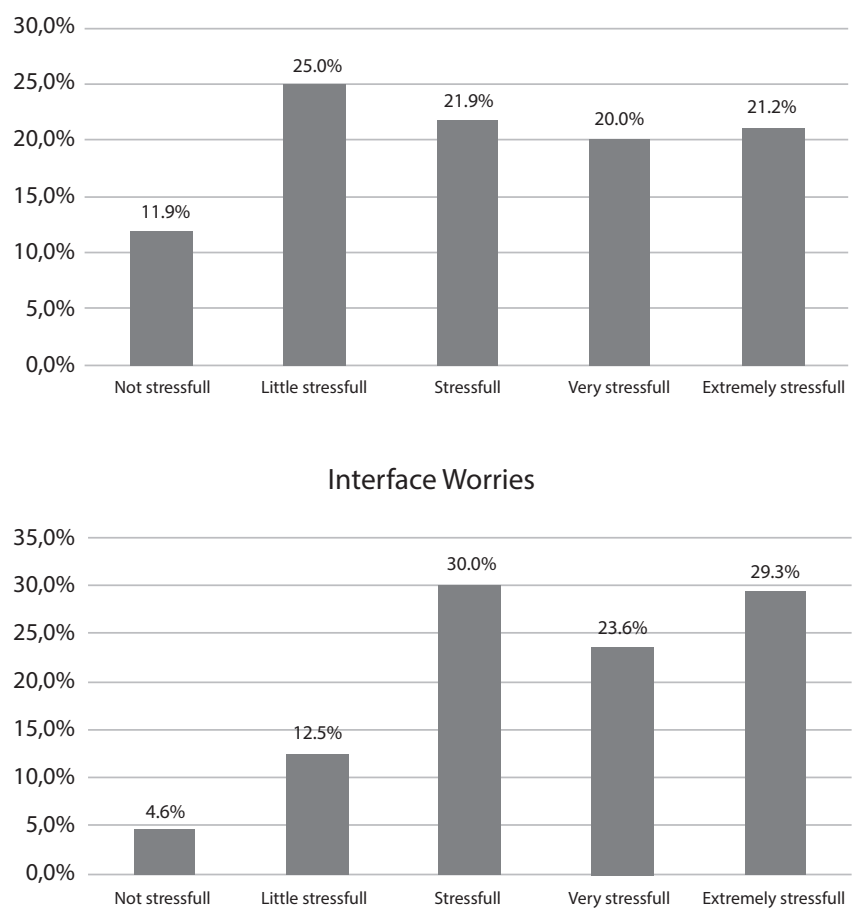

Figure 2 - Frequency distribution of responses for Student Nurse Stress Index (SNSI) -Brazil categories

The predominant sociodemographic characteristics of the students who evaluated the instrument were: female (90\%), average age 22.95 years old, brown (62.5\%), single (87.5\%), from Teresina (70\%) and living in Teresina (97.5\%), lives with 3 people (on average), no children (87.5\%), no income and expenses are financed by family or others ( $82.5 \%)$, unemployed ( $80 \%)$ family 
income ranges from 1 to 2 minimum wages (32.5\%), income greater than 4 minimum wages (27.5\%) (at the time of data collection, the minimum wage was 954 reais).

Regarding the academic variables, most students were in the sixth semester (35\%), chose the nursing course because of job market (39.2\%) and by vocation (31.3\%), studies an average of 11.38 hours per week, sleeps 5.72 hours per day, attends 3 to 4 subjects with a total academic load of 433.25 hours during the semester.

The SNSI - Brazil is composed by 22 items divided into 4 categories: academic load, clinical sources, interface worriers and personal problems that are distributed in groups of questions related to the daily life of the nursing student. Each item is assessed with a Likert scale and the score ranges from not stressful $=1$ to extremely stressful $=5$. Figure 2 illustrates the frequency distribution of responses for each category.

For the Academic Load category, there was a growing pattern in the distribution of responses ranging from "not stressful" $(2.5 \%)$ to "extremely stressful" (34.3\%). The Clinical Sources category had the lowest frequency of "extremely stressful" responses among the other categories, however, this value was the same as"not stressful"(15\%).

In the Personal Problems category, the frequency of responses was similar, except for the item "not stressful" (11.9\%). For Interface Worries, the two highest frequencies were "stressful" (30\%) and "extremely stressful" (29.3\%). In general, it was observed that in all categories most responses were "stressful", "very stressful" and "extremely stressful".

The reliability of the instrument applied was assessed by Cronbach's alpha coefficient and the value obtained was 0.80 . The categories of the instrument were also evaluated individually, as can be seen in Table 3 and the values were below 0.70 .

Table 3 - Cronbach's Alpha Values for Student Nurse Stress Index (SNSI)BRAZIL Categories, Brazil, 2019

\begin{tabular}{cc}
\hline Category & Cronbach's Alpha \\
\hline Academic load & 0.58 \\
Clinical sources & 0.64 \\
Personal problems & 0.62 \\
Interface worries & 0.67 \\
\hline
\end{tabular}

The agreement among the students' evaluations was also assessed with the Fleiss Kappa test and the obtained Kappa value and p-value were 0.74 and 0 (zero), respectively. In their evaluations, some investigated students also answered the question "would you like to add or replace any item in the questionnaire?" And made suggestions regarding items that, in their opinion, should be included in the instrument, such as: extracurricular activities overload (student 06); Substances use (alcohol, etc.) (student 10); Add question about food (student 21); Add some item about commuting to the workplace/internship, as well as about violence (student 26); Student's financial condition regarding stress in student's life (student 34).

\section{DISCUSSION}

In line with the results of the sociodemographic and academic characterization of students, we can cite one study conducted in
Saudi Arabia whose sample consisted of 121 nursing students who had an average age of 21.4 years old ranging from 20 to 24 years old. Most were single (86.8\%) and $95.7 \%$ were unemployed ${ }^{(16)}$.

Another study, conducted in Brazil with 88 undergraduate and bachelor degree nursing students, found that the average age of the students was 22.5 years old, with a standard deviation of 1.07; most participants were female (Bachelor $=96.2 \%$ and Licentiate $=97.2 \%)$; single (Bachelor $=93.9$ and Licentiate $=91.7 \%)$; Catholic $(\text { Bachelor }=64.3 \% \text { and Licentiate }=84.6 \%)^{(6)}$.

In a recent study, we observed that some of these sociodemographic factors were significantly associated with the stress that was presented in most students (64\%), such as: gender $(p<0.010)$, age group $(p<0.029)$, marital status $(p<0.001)$, having children $(p<0.001)$, occupational status $(p<0.001)$, funding of studies $(p<0.009)$ and current year $(p<0.001)^{(5)}$.

During the analysis of the SNSI-Brazil application data, some items stood out in the answers. For example, the items "Amount of classwork material to be learned”, "Difficulty of classwork material to be learned", "Examinations and/or grades" and "Too much responsibility" from the academic load category were not marked as "not stressful" by any of students; and the items "patients' attitudes toward me"," patients' attitudes toward my profession" and "relations with staff in the clinical area" in the clinical sources category were not marked as "extremely stressful" for none of them.

In other studies using the SNSI, they found that for the academic category, women and those without any other education had a higher stress score than men and those with previous education $(p<0.01 \text { and } p<0.05 \text {, respectively })^{(17)}$. Hirsch et al. (2015) pointed out that academic education, practical knowledge deficit and lack of time and leisure were the most significant predictors of stress in their sample, these students used strategies such as denial and escape from reality ${ }^{(18)}$.

It was also found that items related to intrinsic factors to the academic environment, such as college support for students, can become protective factors against stress and consequently against the use of alcohol and other drugs as a coping way ${ }^{(9,17,19)}$.

Comparing all categories of the instrument, a study found that students in the second year of nursing course had greater stress in all categories than students in the first year of the course. Some factors may explain it: More experienced students have higher professional demands because they have greater responsibilities; students raise higher expectations for themselves as they progress through the course; have greater perception and empathy of the patient's situation due to greater knowledge of caregiver roles ${ }^{(17)}$.

The reliability of the SNSI-Brazil obtained values that indicate a good internal consistency $(\alpha=0.80)$ and the categories individually, although presenting values below 0.70 , have an internal consistency considered acceptable ${ }^{(20)}$.

In a study conducted in Turkey, for adaptation and validation of the SNSI, the alpha coefficient value was 0.86 for the instrument as a whole and $0.85,0.83,0.73$ and 0.74 respectively for the personal problems, clinical sources, interface worries, and academic load categories $^{(21)}$.

Some other countries also assessed the internal consistency of the SNSI. For example, in applying the instrument to Indian students, the alpha value was 0.79 and in California it was 0.89 in a sample of 154 students $^{(22-23)}$. 
This shows that the SNSI is a reliable tool for both Brazil and other countries context, as an instrument can be considered reliable if its Alpha coefficient is greater than $0.70^{(24)}$.

In the students' evaluations, the values obtained with the Fleiss Kappa and Kappa tests ( $p$-value $=0.74$ and $p$-value $<0.01$ ) respectively, indicate a substantial agreement among the evaluations.

\section{Limitations of the study}

The study had some limitations such as: the time to perform the study; the communication with the author of the instrument, since he lives in another country; and the low adherence of the judges, as several were invited and a few responded to the invitation, resulting in a small sample and it may have influenced the values of agreement among the judges.

\section{Contributions to the Nursing area}

Among the benefits, we can mention that the knowledge of stressors for nursing students can support the development of coping strategies, influencing academic performance and consequently the performance of this professional when graduated.

\section{CONCLUSION}

Studies on cultural adaptation and validation of measuring instruments are very important for the development of valid and reliable instruments, especially when comparing research results in different cultures.
Instruments that assess stress should be well designed and have adequate psychometric properties due to the multidimensionality and complexity of this phenomenon. Thus, before being used in another context, these instruments must go through a process of translation and cross-cultural adaptation.

The SNSI is an instrument that aims to measure the intensity of stress that some related factors cause in nursing students, encompassing the academic environment, clinical practice, personal interactions in these environments and personal problems. SNSI has been used in several international studies and has shown good internal consistency and reliability.

During this study, an instrument translated and adapted to the Brazilian context (SNSI - Brazil) with good internal consistency, reliability, face and content validity was obtained as a result.

In addition, the results of the application of this instrument allowed a visualization of the most stressful factors for nursing students in Brazil evaluated, such as amount of classwork material to be learned, examinations and/or grades, competition with classmates, lack of free time, fear of failing a course, too much responsibility and not having enough time for family.

Knowing these stress-related factors can support the planning and implementation of stress coping strategies within and outside the academic environment, which can directly influence students' academic performance, future professionals being trained, and possibly in the care that will be provided by them.

Therefore, some steps still need to be developed. A validation study of the translated and adapted instrument with a larger sample of both judges and students is necessary, as well as the establishment of cutoff points for the evaluation of the scores obtained with the summation of the answers of the items.

\section{REFERENCES}

1. Andolhe R, Barbosa RL, Oliveira EM, Costa ALS, Padilha KG. Stress, coping and burnout among Intensive Care Unit nursing staff: associated factors. Rev Esc Enferm USP. 2015;49(spe):58-64. doi: 10.1590/S0080-623420150000700009

2. Kumar A, Pore P, Gupta S, Wani AO. Level of stress and its determinants among Intensive Care Unit staff. Indian J Occup Environ Med. 2016;20(3):129-32. doi: 10.4103/0019-5278.203137.

3. Silva GAV, Silva GSA, Silva RM, Andolhe R, Padilha KG, Costa ALS. Estresse e coping entre profissionais de enfermagem de unidades de terapia intensiva e semi-intensiva. Rev Enferm UFPE. 2017;11(Supl. 2):922-31. doi: 10.5205/relou.10263-91568-1-RV.1102sup201707

4. Leonelli LB, Andreoni S, Martins P, Kozasa EH, Salvo VL, Sopezki D, Marin JM, Campayo JG, Demarzo MMP. Estresse percebido em profissionais da Estratégia de Saúde da Família. Rev Bras Epidemiol. 2017;20(2):286-98. doi: 10.1590/1980-5497201700020009

5. Cestari VRF, Barbosa IV, Florencio RS, Pessoa VLMP, Moreira TMM. Estresse em estudantes de enfermagem: estudo sobre vulnerabilidades sociodemográficas e acadêmicas. Acta paul. enferm. São Paulo. 2017; 30(2):190-6. doi: 10.1590/1982-0194201700029

6. Moreira DP, Furegato ARF. Estresse e depressão entre alunos do último período de dois cursos de enfermagem. Rev Latino-Am Enfermagem. 2013;21(esp):8 telas. doi: 10.1590/S0104-11692013000700020

7. Cohen S, Williamsom GM. Perceived Stress in a Probability Sample of United States. In: Spacapan S, Oskamp S, (eds). The Social Psychology of Health: Claremont Symposium on applied social psychology. Newbury Park, CA: Sage; 1988.

8. Jones MC, Johnston DW. The derivation of a brief Student Nurse Stress Index. Work Stress. 1999;13(2):162-81. 1999. doi: $10.1080 / 026783799296129$

9. Boulton M, O'Connell KA. Nursing Students' Perceived Faculty Support, Stress and Substance Misuse. J Nurs Educ. 2017;56(7):404-11. doi: 10.3928/01484834-20170619-04

10. Beaton D, Bombardier C, Guillemin F, Ferraz MB. Recommendations for the Cross-cultural Adaptation of the DASH \& QuickDASH outcome measures. Institute for Work \& Health 2007. Available from: http://www.dash.iwh.on.ca/translate2.htm.

11. VU University Medical Center, Istitute for Health and Care Research. The COSMIN Checklist [Internet]. Available from: www.cosmin.nl 
12. Waltz CF, Strickland O, Lenz ER. Measurement in nursing and health research. O J Psychiatr. 2010; 3(3). Available from: https://www.scirp.org/ (S(i43dyn45teexjx455qlt3d2q))/reference/ReferencesPapers.aspx?ReferencelD=851372.

13. Fleiss JL. Measuring nominal scale agreement among many raters. Psychological Bulletin. 1971;76(5):378-382. doi: 10.1037/h0031619

14. Pontius R, Millones M. Death to Kappa: birth of quantity disagreement and allocation disagreement for accuracy assessment. International Journal of Remote Sensing. 2011; 32(15):4407-4429. doi: 10.1080/01431161.2011.552923

15. Landis JR, Koch GG. The measurement of observer agreement for categorical data. Biometrics.1977;33(1):159-174. Available from: http:// www.jstor.org/stable/2529310

16. Al-Gamal E, Alhosain A, Alsunaye K. Stress and coping strategies among Saudi nursing students during clinical education. Perspective Psychiatric Care. 2018;54(2):198-205. doi: 10.1111/ppc.122223

17. Tully A. Stress, sources of stress and ways of coping among psychiatric nursing students. J Psychiatr Mental Health Nurs. 2004;11(1):43-47. doi: 10.1111/j.1365-2850.2004.00682.x

18. Hirsch CD, Barlem ELD, Tomaschewski-Barlem JG, Lunardi VL, Oliveira ACC. Preditores do estresse e estratégias de coping utilizadas por estudantes de Enfermagem. Acta Paul Enferm. São Paulo. 2015;28(3):224-9. doi: 10.1590/1982-0194201500038

19. Far MS, Khah HZH, Moradbeigi K, Moadab NH, Ghassemi M, Cheraghian B, Elhami S. Clinical instructor social support and nursing student stress in clinical environments. Int J Adv Biotechnol Res. 2017;8(1):182-8.

20. Cummings SR, Stewart A, Rulley SB. Elaboração de questionários e instrumentos de coleta de dados. In: Hulley SB. Delineando a pesquisa clínica. Uma abordagem epidemiológica. Porto Alegre: Artmed. 2003; 265-281.

21. Sarikoc G, Demiralp MB, Oksuz E, Pazar B. Turkish Version of the Student Nurse Stress Index: Validity and Reliability. Asian Nurs Res. 2017; 11(2):128-133. doi: 10.1016/j.anr.2017.05.006

22. Shukla A, Kalra GS, Pakhare A. Understanding stress and coping mechanisms in Indian student nurses. Sri Lanka J Psychiatr. 2013;4(2):29-33. 2013. doi: 10.4038/sljpsyc.v4i2.5387.

23. Baker ML. Nursing student stress and demographic factors [thesis]. San Marcos (CA): School of Nursing, California State University; 2012.

24. Tavakol M, Dennick R. Making Sense of Cronbach's Alpha. Int J Med Educ. 2011;2:53-55. doi: 10.5116/ijme.4dfb.8dfd 53 